\title{
Optimal planning strategy among various arc arrangements for prostate stereotactic body radiotherapy with volumetric modulated arc therapy technique
}

\author{
Sang Won Kang1,2, Jin Beom Chung ${ }^{3}$, Jae Sung Kim³, In Ah Kim³, Keun Yong Eom³, \\ Changhoon Song ${ }^{3}$, Jeong Woo Lee ${ }^{4}$, Jin Young Kim5 ${ }^{5}$, Tae Suk Suh ${ }^{1,2}$ \\ ${ }^{1}$ Research Institute of Biomedical Engineering, College of Medicine, The Catholic University of Korea, Seoul, Korea \\ ${ }^{2}$ Department of Biomedical Engineering, College of Medicine, The Catholic University of Korea, Seoul, Korea \\ ${ }^{3}$ Department of Radiation Oncology, Seoul National University Bundang Hospital, Seongnam, Korea \\ ${ }^{4}$ Department of Radiation Oncology, Konkuk University Medical center, Seoul, Korea \\ ${ }^{5}$ Department of Radiation Oncology, Haeundae Paik Hospital, Inje University, Busan, Korea
}

Radiol Oncol 2017; 51(1): 112-120.

Received 19 July 2016

Accepted 25 October 2016

Correspondence to: Jin-Beom Chung, Department of Radiation Oncology, Seoul National University Bundang Hospital, Seongnam, 13620 , Korea. E-mail: jbchung1213@gmail.com and Tae Suk Suh, Department of Biomedical Engineering, College of Medicine, The Catholic University of Korea, Seoul, 137701, Korea. E-mail: suhsanta@catholic.ac.kr

Disclosure: No potential conflicts of interest were disclosed.

Jin Beom Chung and Tae Suk Suh contribution equally to this work

Backgorund. The aim of this study was to determine the optimal strategy among various arc arrangements in prostate plans of stereotactic body radiotherapy with volumetric modulated arc therapy (SBRT-VMAT).

Patients and Methods. To investigate how arc arrangements affect dosimetric and biological metrics, SBRTVMAT plans for eighteen patients were generated with arrangements of single-full arc (1FA), single-partial arc (1PA), double-full arc (2FA), and double-partial arc (2PA). All plans were calculated by the Acuros XB calculation algorithm. Dosimetric and radiobiological metrics for target volumes and organs at risk (OARs) were evaluated from dosevolume histograms.

Results. All plans were highly conformal $(\mathrm{Cl}<1.05, \mathrm{CN}=0.91)$ and homogeneous $(\mathrm{HI}=0.09-0.12)$ for target volumes. For OARs, there was no difference in the bladder dose, while there was a significant difference in the rectum and both femoral head doses. Plans using IPA and 2PA showed a strong reduction to the mean rectum dose compared to plans using IFA and 2FA. Contrastively, the $D_{2 \%}$ and mean dose in both femoral heads were always lower in plans using IFA and 2FA. The average tumor control probability and normal tissue complication probability were comparable in plans using all arc arrangements.

Conclusions. The use of IPA had a more effective delivery time and produced equivalent target coverage with better rectal sparing, although all plans using four arc arrangements showed generally similar for dosimetric and biological metrics. However, the $\mathrm{D}_{2 \%}$ and mean dose in femoral heads increased slightly and remained within the tolerance. Therefore, this study suggests that the use of IPA is an attractive choice for delivering prostate SBRT-VMAT.

Key words: stereotactic body radiotherapy; volumetric modulated arc therapy; prostate cancer; arc arrangement; dosimetric and biological metrics

\section{Introduction}

Prostate cancer is the most common cancer in men, accounting for over one fifth of male cancer diag- noses, with the number of prostate cancer patients rapidly increasing. Various radiotherapy techniques for treating prostate cancer have been considered effective noninvasive treatment options, 
especially for elderly patients and those unfit for surgery. ${ }^{1-3}$

Radiation therapy options for prostate cancer include external beam radiation therapy (EBRT) and brachytherapy. Volumetric modulated arc therapy (VMAT) and intensity-modulated radiation therapy (IMRT) for EBRT is widely used as the standard treatment for prostate cancer. VMAT and IMRT permit dose optimization, in which the dose to the prostate can be increased while reducing toxicities and doses to the rectum and bladder, resulting in improved local control and reduced complications when compared to three-dimensional conformal radiation therapy (3DCRT). ${ }^{4-7}$ In addition, VMAT can produce equivalent or even better target coverage and normal tissue sparing compared to fixedfield IMRT while taking advantage of more efficient monitor unit (MU) and reducing the delivery times.

The use of SBRT to irradiate primary or metastatic tumors in several anatomical sites is becoming the standard treatment. ${ }^{8-13}$ SBRT with VMAT (SBRT-VMAT) is a radiotherapy method, which very precisely delivers a high dose of radiation to the target area in either a single dose or a small number of fractions. It is an attractive approach to dose escalation. Recently, researchers using SBRT, including the linear accelerator (Linac) and CyberKnife $(\mathrm{CK})$, have achieved promising results in the treatment of prostate cancer. ${ }^{14-17}$ To our knowledge, there is very little information regarding the optimal planning for various arc arrangements of prostate SBRT-VMAT. ${ }^{18,19}$ Moreover, there is no study, which investigates the radiobiological effect of prostate SBRT-VMAT plans.

The aim of this study is to determine the optimal treatment planning approach under the different arc arrangements by analyzing the dosimetric and radiobiological impact in plans for prostate SBRTVMAT.

\section{Patients and methods}

\section{Patient selection and contouring}

For this retrospective study, we chose 18 patients diagnosed with prostate cancer that had previously been treated in our department from September 2013 to October 2015. All prostate cancer patients were enrolled in our SBRT planning study, which was approved by the institutional review board of Seoul National University Bundang Hospital. (IRB No. B-1501/284-107).

A computer tomography (CT; The Brilliance CT Big Bore, Philips, Eindhoven, Netherlands) simu- lation was performed with the patients, who were placed in a supine position on a flat bench and stabilized with Knee-fix ${ }^{\mathrm{TM}}$ and Feet-fix ${ }^{\mathrm{TM}}$ (CIVCO Medical Solutions, Coralville, IA, USA). Prior to the CT simulation, the patients were asked to drink $300 \mathrm{ml}$ of water $1 \mathrm{~h}$ before the simulation to ensure that the bladder was completely filled. An endorectal balloon (ERB) was inserted into the rectum and filled with $70 \mathrm{cc}$ of air. After $1 \mathrm{~min}$, the ERB catheter was placed at the pre-marked position and the inflated ERB was immobilized above the anal sphincter. A detailed description of the patient setup was given in our previous study. ${ }^{20,21}$ The CT scans were acquired with a $3 \mathrm{~mm}$ slice thickness. The prostatic bed was delineated as the clinical target volume (CTV), and the planning target volume (PTV) was defined as the CTV plus a treatment margin of 7 $\mathrm{mm}$ posteriorly and $10 \mathrm{~mm}$ in all other directions. The relevant normal tissue including rectum, bladder, and femoral head were delineated as OARs. The rectum was defined as extending from the sigmoid flexure to the bottom of the ischium.

\section{Planning strategy for SBRT}

Prostate SBRT using VMAT plans were created by the Eclipse ${ }^{\mathrm{TM}}$ Treatment Planning System (ver. 11.0.34, Varian Medical Systems). The SABRVMAT planning system was commissioned for a Truebeam $^{\mathrm{TM}}$ Linac (Varian Medical Systems) with a high definition multileaf collimator (HD MLC). Dose distributions were calculated using a 10-MV flattening-filter-free (FFF) beam and the Acuros XB (AXB) dose calculation algorithm with inhomogeneity correction. The calculation grid size was 2.5$\mathrm{mm}$.

The SBRT-VMAT plans were set up with four arc arrangements such as single-full arc $\left(181^{\circ}\right.$ to $179^{\circ}$; $1 \mathrm{FA})$, single-partial arc $\left(240^{\circ}\right.$ to $120^{\circ}$; $\left.1 \mathrm{PA}\right)$, doublefull $\operatorname{arcs}\left(181^{\circ}\right.$ to $179^{\circ}$ and $179^{\circ}$ to $\left.181^{\circ} ; 2 \mathrm{FA}\right)$, and double-partial $\operatorname{arcs}\left(240^{\circ}\right.$ to $120^{\circ}$ and $120^{\circ}$ to $240^{\circ}$; 2PA). The arc arrangements for SBRT-VMAT plans are presented in Figure $1 \mathrm{~A}$ to D. The collimator rotation angles were $30^{\circ}$.

The prescription dose was $42.7 \mathrm{~Gy}$ and was administered in seven fractions. Compared to 78 Gy in 39 fractions, which is the standard prostate fractionation, this delivers a higher biologically effective dose (BED) to the prostate (216.3 Gy vs. $182.0 \mathrm{~Gy} ; \alpha / \beta 1.2 \mathrm{~Gy})$ but an equivalent dose to late responding tissues (129.5 Gy vs. $130.0 \mathrm{~Gy} ; \alpha / \beta 3.0$ Gy). For all cases, a minimum of $95 \%$ of the prescription dose (40.6 Gy) was assigned to cover $95 \%$ of the PTV $\left(\mathrm{V}_{95 \%} \geq 95 \%\right)$. No OAR constraints for 
prostate SBRT have yet been reported. Therefore, we used the modified constraints for the OARs derived from those reported by Murray et al. ${ }^{22}$ that were suitable for our planning study. The OAR constraints for this planning study are listed in Table 1.

\section{Evaluation of dosimetric and biological parameters}

The mean, maximum, and minimum doses for PTV were measured from cumulative dose-volume histograms (DVH) of plans using four arc arrangements for all patients. In order to investigate the target coverage, $\mathrm{V}_{100 \%}$ for CTV and PTV were evaluated.

The conformity index (CI) was defined as follows:

$$
C I=\frac{V_{R I}}{T V}
$$

The ideal conformity is defined as $\mathrm{CI}=1$. A value of $\mathrm{CI}>1$ indicated that healthy tissue has been irradiated..$^{23}$ The conformation number $(\mathrm{CN})$ takes into consideration the irradiation of healthy tissue. It is the product of two fractions, $\mathrm{TV}_{\mathrm{RI}} / \mathrm{TV}$ and $\mathrm{TV}_{\mathrm{RI}} / \mathrm{V}_{\mathrm{RI}}$, where TV is the volume of the PTV, $\mathrm{TV}_{\mathrm{RI}}$ is the volume of the PTV covered by the reference isodose line, and $\mathrm{V}_{\mathrm{RI}}$ is the volume enclosed by the reference isodose line. $\mathrm{TV}_{\mathrm{RI}} / \mathrm{TV}$ is the quality of the target coverage and $\mathrm{TV}_{\mathrm{RI}} / \mathrm{V}_{\mathrm{RI}}$ is the volume of healthy tissue irradiated with the reference isodose ( $95 \%$ of prescribed dose) or more. ${ }^{24}$

The dose homogeneity index $(\mathrm{HI})$ was determined as follows:

$$
H I=\frac{\left(D_{5 \%}-D_{95 \%}\right)}{D_{50 \%}}
$$

where $D_{5 \%}$ is the maximum dose received by $5 \%$ of PTV, $\mathrm{D}_{95 \%}$ is the minimum dose received by $95 \%$ of PTV, and $\mathrm{D}_{50 \%}$ is the dose received by $50 \%$ of PTV. A lower HI represents a more homogeneous plan, because $\mathrm{D}_{5 \%}$ and $\mathrm{D}_{95 \%}$ were surrogate markers of maximum dose and minimum dose in the PTV, respectively.

The near-to-maximum dose $\left(\mathrm{D}_{2 \%}\right)$ and mean dose for the OARs were evaluated. In addition, we conducted a detailed analysis of the rectum and bladder volumes that received at least $95 \%\left(\mathrm{~V}_{95 \%}\right)$, $80 \%\left(\mathrm{~V}_{80 \%}\right), 50 \%\left(\mathrm{~V}_{50 \%}\right)$, and $20 \%\left(\mathrm{~V}_{20 \%}\right)$ of the prescription dose; these values represent very high, high, intermediate, and low doses, respectively. In addition, total monitor units (MUs) were compared in each plan between single arc and double arc arrangements.
TABLE 1. Dose volume constraints adopted for planning study

\begin{tabular}{llll}
\hline Volume & Rectum & Bladder & Femoral heads \\
\hline \multirow{4}{*}{ Constraints } & $\mathrm{V}_{42.7 \mathrm{~Gy}(100 \%)}<5 \%$ & $\mathrm{~V}_{42.7 \mathrm{~Gy}(100 \%)}<10 \%$ & $\mathrm{~V}_{29.9 \mathrm{~Gy}(70 \%)}<50 \%$ \\
& $\mathrm{~V}_{38.4 \mathrm{~Gy}(90 \%)}<15 \%$ & $\mathrm{~V}_{34.7 \mathrm{~Gy}(81 \%)}<25 \%$ & $\mathrm{D}_{\max }<29.9 \mathrm{~Gy}$ \\
& $\mathrm{~V}_{32.0 \mathrm{~Gy}(75 \%)}<35 \%$ & $\mathrm{~V}_{29.9 \mathrm{~Gy}(70 \%)}<50 \%$ & \\
& $\mathrm{~V}_{28.0 \mathrm{~Gy}(65 \%)}<45 \%$ & & \\
& $\mathrm{~V}_{24.8 \mathrm{~Gy}(58 \%)}<70 \%$ & & \\
& $\mathrm{~V}_{20.0 \mathrm{~Gy}(47 \%)}<80 \%$ & & \\
\hline
\end{tabular}

$D_{\max }=$ the maximum dose $; V_{x x}=$ the volume receiving dose of $x x G y$ ( $x \%$ of the prescription dose)

For the radiobiological model evaluation, we utilized the MATLAB program to calculate the Niemierko's equivalent uniform dose (EUD)-based tumor control probability (TCP) and normal tissue complication probability (NTCP). ${ }^{25,26}$ According to Niemierko's phenomenological model, the EUD is defined as follows:

$$
\mathrm{EUD}=\left(\sum_{i}\left(v_{i} E Q D_{i}^{\alpha}\right)\right)^{\frac{1}{\alpha}}
$$

where $\alpha$ is a tissue-specific parameter describing the volume effect, and is the partial tumor volume, which receives dose D in Gy. For tumors, $\alpha$ takes negative values; for serial-like structures, $\alpha$ takes large positive values; and for parallel-like structures, $\alpha$ takes values close to 1 .

The prostate TCP was calculated with Niemierko's EUD-based TCP. The equation is defined as follows:

$$
\mathrm{TCP}=\frac{1}{1+\left(\frac{T C D_{50}}{E U D}\right)^{\gamma_{50}}}
$$

where $T C D_{50}$ is the tumor dose to control $50 \%$ of the tumors when the tumor is homogeneously irradiated, and the $\gamma_{50}$ is the slope of dose response at a TCP of $50 \%$. NTCP for OARs were calculated using Niemierko's EUD-based NTCP with the following equation:

$$
\mathrm{NTCP}=\frac{1}{1+\left(\frac{T D_{50}}{E U D}\right)^{\gamma_{50}}}
$$

where $T D_{50}$ is the tolerance dose for a $50 \%$ complication rate at a specific time interval (e.g., 5 years in the Emami et al. normal tissue tolerance data ${ }^{27}$ ) when the whole organ of interest is homogenously irradiated. The $\gamma_{50}$ is specific to the normal structure of interest and describes the slope of the doseresponse curve.

Table 2 lists parameters used to calculate Niemierko's EUD-based TCP and NTCP. These 
TABLE 2. Parameters used to calculated Niemierko's EUD-based TCP and NTCP

\begin{tabular}{|c|c|c|c|c|c|c|c|c|}
\hline Tissue & $100 \%$ dpf (Gy) & Fraction (\#) & $\alpha$ & $\gamma_{50}$ & $\begin{array}{l}T D_{50} \\
(G y)\end{array}$ & $\begin{array}{l}T C D_{50} \\
(G y)\end{array}$ & dpf (Gy) & $\begin{array}{c}\alpha / \beta \\
\text { (Gy) }\end{array}$ \\
\hline Prostate & 6.1 & 7 & -10 & 1.0 & & 28.34 & 2 & 1.20 \\
\hline Rectum & 6.1 & 7 & 8.33 & 4 & 80 & & 2 & 3.90 \\
\hline Bladder & 6.1 & 7 & 2 & 4 & 80 & & 2 & 8.00 \\
\hline Femur & 6.1 & 7 & 4 & 4 & 65 & & 2 & 0.85 \\
\hline
\end{tabular}

$\frac{\alpha}{\beta}=$ Alpha-beta ratio; $100 \% \mathrm{dpf}=100 \%$ dose per fraction; $\mathrm{dpf}=$ Parameters' source data's dose per fraction

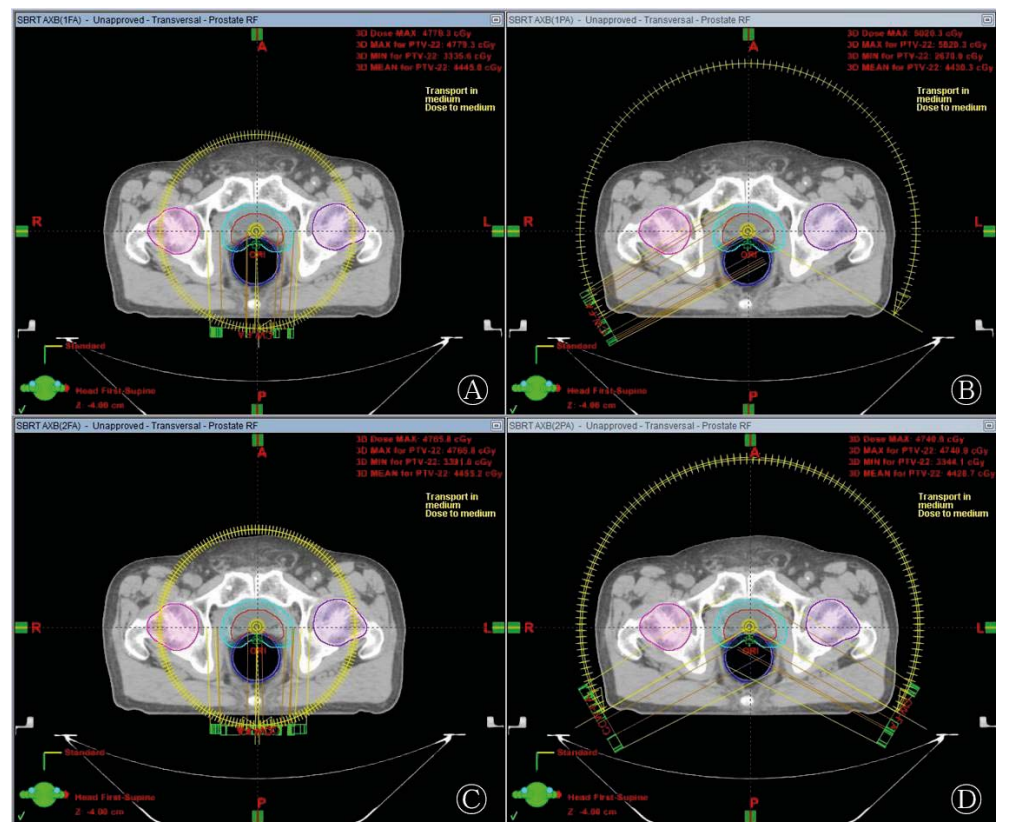

FIGURE 1. An arrangement of (A) one full $\operatorname{arc}(1 F A),(B)$ one partial arc (IPA), (C) two full arcs (2FA), and (D) two partial arcs (2PA) in prostate SBRT-VMAT for the same patient. of the four arc arrangements of all patients were very similar as shown in Table 3 and Figure 3A. In four arc arrangements, the volume of the CTVs that received $100 \%$ of prescription dose was greater than $97.6 \%$ (range 96.7-98.4\%), which indicated very good coverage the CTV in the VMAT plan. All plans were highly conformal with $\mathrm{CI}<1.05$ and $\mathrm{CN}=0.91$, and the doses were homogeneous $(\mathrm{HI}=$ $0.09 \pm 0.12$ ).

The doses to bladder tissue showed no difference among all arc arrangements. However, there were significant differences in the doses of the rectum, left and right femoral head (Table 4, Figure 3 A, C, D, E). Compared to 1FA and 2FA, 1PA and 2PA arrangements resulted in a significant reduction of the mean dose $\left(\mathrm{V}_{50 \%}\right)$ of the rectum. These arc arrangements resulted in a significant increase in the near-to-maximum dose $\mathrm{D}_{2 \%}$ and mean dose of the left and right femoral head.

Table 5 summarizes the MUs and delivery time for the prostate SBRT plans using the four arc arrangements. The average MU was $1575 \pm 63,1607$ $\pm 56,1646 \pm 97$, and $1660 \pm 98$ for plan using 1FA, 1PA, 2FA, and 2PA, respectively. Plans using 1FA required lower MUs than those using other arc arrangements. The average delivery time was $1.01 \pm$ $0.02,0.69 \pm 0.01,2.00 \pm 0.01$, and $1.36 \pm 0.02$ for $1 F A$, 1PA, 2FA, and 2PA, respectively. The ratio of delivery time was $1.46,2.90$, and 1.97 for $1 F A, 2 F A$, and 2PA compared to 1PA.

The average TCP of prostate tumors and the average NTCP of OARs in the four arc arrangement plans are shown in Table 6. TCP and NTCP values were comparable for all arc arrangements. achieved with four arc arrangements for the patient. There were small differences in the dose distributions and corresponding DVHs among each arc arrangement. Average cumulated DVHs of the PTV, rectum, bladder, and left and right femoral head are presented in Figure 3A to 3E for each of the four arc arrangements.

Tables 3 and 4 show the average (range) values for the dosimetric results of target volumes and several OARs (i.e., bladder, rectum, and left and right femoral head). The resulting PTV and CTV

\section{Discussion}

Much has been published regarding the use of VMAT in prostate cancer, but little regarding the use of SBRT using VMAT for prostate cancer. Most of the previous studies for prostate SBRT employed the $\mathrm{CK}$ technique. The $\mathrm{CK}$ technique is an 
accurate image guided method for delivering radiation to a precisely targeted area using multiple nonisocentric beams with steep surrounding dose gradient. ${ }^{16,29}$

In the previous study reported by Chow and Jiang $^{30}$, the dosimetry and radiobiological model variation was investigated in prostate VMAT plans using the single- and double-full arc technique. The authors reported that the double-arc technique could lower the dose-volume criteria of the rectum and bladder but increase the rectal NTCP.

In addition to the study above, we included the single and double-partial arc (1PA and 2PA), which avoided irradiation of the rectum for the optimal prostate SBRT-VMAT plan. This study focused on arc arrangements as a key preparatory step in facilitating clinical planning studies.

The prostate SBRT-VMAT plans for all arc arrangements generated conformal dose distributions for target volumes (PTV and CTV). We found that the dose distributions in the anterior and posterior direction were lower when the partial arc arrangements (1PA and 2PA) were used instead of the full arc (1FA and 2FA). In contrast, the dose distributions in the left and right direction for full arc arrangements were lower than those of the partial arc (Figure 2). This was due to the application of arc angles, which avoided the direct irradiation of the rectum.

With respect to the dose to the OARs, the effect of the dose difference on bladder tissue was negligible for the different arc arrangements. The differences between the partial and full arc arrangements were observed in several dose-volume criteria (e.g., $\mathrm{V}_{20 \%}$ and $\mathrm{V}_{50 \%}$ ) and were slightly lower in plans using the partial arc arrangements than the full arc arrangements. For the rectum, the partial arc arrangements showed relatively strong reductions of the mean dose compared to the full arc arrangements while all plans using four arc arrangements showed no dramatic differences in the high and low doses. For the left and right femoral head in Table 3, Figures $3 \mathrm{D}, \mathrm{E}$, we found that the $\mathrm{D}_{2 \%}$ and mean dose were always lower when the full arc arrangements were used compared to the partial arc arrangements. We also observed better sparing in the right femoral head compared to the left femoral head.

The clinical delivery time of prostate SBRTVMAT plans using the one arc arrangements (1FA and 1PA) was approximately half compared to that of the two arc arrangements (2FA and 2PA). The reduced delivery time by using one arc arrangements has the potential to decrease the effects of intrafractional motion because prostate motion is
TABLE 3. Dosimetric results for target volumes in prostate SABR-VMAT plans using four arc arrangements

\begin{tabular}{|c|c|c|c|c|}
\hline & \multicolumn{4}{|c|}{ Avg $\pm S D$ (range) } \\
\hline & 1FA & IPA & $2 \mathrm{FA}$ & $2 \mathrm{PA}$ \\
\hline \multicolumn{5}{|l|}{ CTV coverage } \\
\hline$D_{50 \%}(G y)$ & $\begin{array}{c}44.9 \pm 0.4 \\
(44.4-45.4)\end{array}$ & $\begin{array}{c}44.6 \pm 0.5 \\
(44.1-45.1)\end{array}$ & $\begin{array}{c}44.5 \pm 0.5 \\
(44.0-45.3)\end{array}$ & $\begin{array}{c}44.4 \pm 0.3 \\
(44.0-44.7)\end{array}$ \\
\hline$D_{5 \%}(G y)$ & $\begin{array}{c}46.0 \pm 0.1 \\
(45.9-46.1)\end{array}$ & $\begin{array}{c}45.9 \pm 0.1 \\
(45.7-46.0)\end{array}$ & $\begin{array}{c}45.9 \pm 0.1 \\
(45.8-46.0)\end{array}$ & $\begin{array}{c}45.8 \pm 0.2 \\
(45.7-45.9)\end{array}$ \\
\hline$D_{95 \%}(G y)$ & $\begin{array}{c}43.5 \pm 0.5 \\
(43.0-44.2)\end{array}$ & $\begin{array}{c}43.1 \pm 0.4 \\
(42.8-43.5)\end{array}$ & $\begin{array}{c}43.1 \pm 0.6 \\
(42.6-43.9)\end{array}$ & $\begin{array}{c}42.8 \pm 0.2 \\
(42.7-43.1)\end{array}$ \\
\hline$V_{100 \%}(\%)$ & $\begin{array}{c}98.4 \pm 1.8 \\
(95.5-100.0)\end{array}$ & $\begin{array}{c}97.9 \pm 0.0 \\
(95.0-99.8)\end{array}$ & $\begin{array}{c}97.8 \pm 3.8 \\
(95.2-100.0)\end{array}$ & $\begin{array}{c}97.6 \pm 2.0 \\
(94.2-99.9)\end{array}$ \\
\hline \multicolumn{5}{|l|}{ PTV coverage } \\
\hline $\mathrm{D}_{\text {mean }}$ & $\begin{array}{c}44.3 \pm 0.2 \\
(44.2-44.6)\end{array}$ & $\begin{array}{c}44.2 \pm 0.1 \\
(44.0-44.4)\end{array}$ & $\begin{array}{c}44.1 \pm 0.3 \\
(44.0-44.6)\end{array}$ & $\begin{array}{c}44.3 \pm 0.1 \\
(44.2-44.5)\end{array}$ \\
\hline$D_{\max }$ & $\begin{array}{c}48.8 \pm 0.8 \\
(47.8-49.8)\end{array}$ & $\begin{array}{c}49.5 \pm 0.9 \\
(48.4-50.5)\end{array}$ & $\begin{array}{c}48.5 \pm 1.1 \\
(47.2-50.0)\end{array}$ & $\begin{array}{c}49.0 \pm 1.4 \\
(47.4-50.5)\end{array}$ \\
\hline Dmin & $\begin{array}{c}33.0 \pm 0.4 \\
(32.4-33.2)\end{array}$ & $\begin{array}{c}32.3 \pm 0.0 \\
(31.9-33.7)\end{array}$ & $\begin{array}{c}32.8 \pm 0.8 \\
(32.1-33.9)\end{array}$ & $\begin{array}{c}33.7 \pm 0.3 \\
(33.4-34.1)\end{array}$ \\
\hline$D_{50 \%}(G y)$ & $\begin{array}{c}44.6 \pm 0.3 \\
(44.2-45.0)\end{array}$ & $\begin{array}{c}44.5 \pm 0.2 \\
(44.3-44.8)\end{array}$ & $\begin{array}{c}44.4 \pm 0.4 \\
(44.1-45.0)\end{array}$ & $\begin{array}{c}44.5 \pm 0.2 \\
(44.3-44.8)\end{array}$ \\
\hline $\mathrm{D}_{5 \%}(\mathrm{~Gy})$ & $\begin{array}{c}46.1 \pm 0.2 \\
(45.9-46.3)\end{array}$ & $\begin{array}{c}46.1 \pm 0.1 \\
(45.9-46.2)\end{array}$ & $\begin{array}{c}46.1 \pm 0.2 \\
(45.9-46.3)\end{array}$ & $\begin{array}{c}46.0 \pm 0.1 \\
(45.9-46.2)\end{array}$ \\
\hline$D_{95 \%}(G y)$ & $\begin{array}{c}41.5 \pm 0.3 \\
(41.1-41.8)\end{array}$ & $\begin{array}{c}41.4 \pm 0.2 \\
(41.2-41.8)\end{array}$ & $\begin{array}{c}41.3 \pm 0.3 \\
(41.0-41.7)\end{array}$ & $\begin{array}{c}41.7 \pm 0.1 \\
(41.6-41.9)\end{array}$ \\
\hline$V_{100 \%}(\%)$ & $\begin{array}{c}87.5 \pm 1.9 \\
(85.1-90.2)\end{array}$ & $\begin{array}{c}86.6 \pm 1.2 \\
(85.0-87.8)\end{array}$ & $\begin{array}{c}87.7 \pm 1.5 \\
(85.8-89.3)\end{array}$ & $\begin{array}{c}88.1 \pm 1.0 \\
(87.1-89.9)\end{array}$ \\
\hline $\begin{array}{l}\text { Conformity } \\
\text { index }\end{array}$ & $\begin{array}{l}1.05 \pm 0.00 \\
(1.02-1.03)\end{array}$ & $\begin{array}{l}1.04 \pm 0.01 \\
(1.02-1.04)\end{array}$ & $\begin{array}{c}1.03 \pm 0.01 \\
(1.02-1.04)\end{array}$ & $\begin{array}{c}1.05 \pm 0.01 \\
(1.02-1.03)\end{array}$ \\
\hline $\begin{array}{l}\text { Conformation } \\
\text { number }\end{array}$ & $\begin{array}{c}0.91 \pm 0.01 \\
(0.90-0.92)\end{array}$ & $\begin{array}{c}0.91 \pm 0.01 \\
(0.09-0.92)\end{array}$ & $\begin{array}{c}0.91 \pm 0.01 \\
(0.91-0.92)\end{array}$ & $\begin{array}{c}0.91 \pm 0.01 \\
(0.90-0.93)\end{array}$ \\
\hline $\begin{array}{l}\text { Homogeneity } \\
\text { index }\end{array}$ & $\begin{array}{c}0.10 \pm 0.01 \\
(0.09-0.12)\end{array}$ & $\begin{array}{c}0.11 \pm 0.00 \\
(0.10-0.11)\end{array}$ & $\begin{array}{l}0.11 \pm 0.01 \\
(0.10-0.12)\end{array}$ & $\begin{array}{c}0.10 \pm 0.00 \\
(0.09-0.10)\end{array}$ \\
\hline
\end{tabular}

Avg. = average; $D_{5 \%}=$ the dose received at least $5 \%$ volume; $D_{\text {mean }}=$ the mean dose; $D_{\text {max }}=$ the maximum dose; $D_{\text {min }}=$ the minimum dose; $D_{50 \%}=$ the dose received at least $50 \%$ volume; $D_{95 \%}=$ the dose received at least $95 \%$ volume; $S D=$ the standard deviation; $\mathrm{V}_{100 \%}=$ the volume received $100 \%$ of prescription dose.

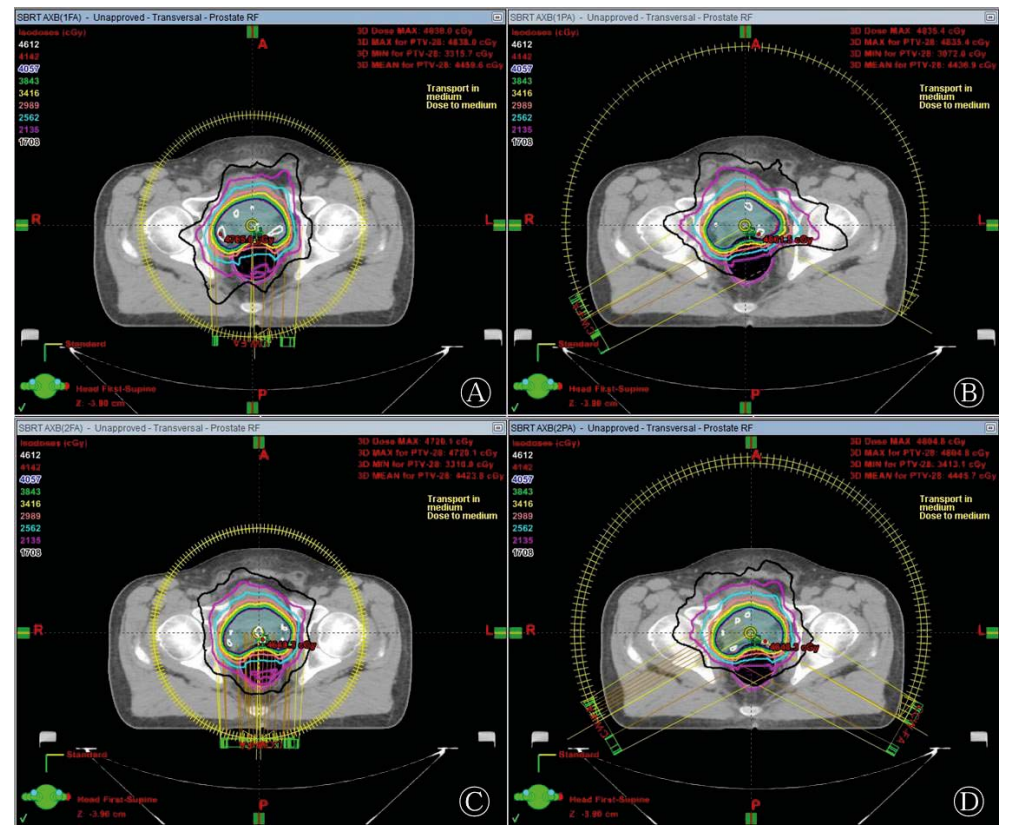

FIGURE 2. An example of the dose distributions achieved with (A) one full arc (IFA), (B) one partial arc (IPA), (C) two full arcs (2FA), and (D) two partial arcs (2PA) arrangement in prostate SBRT-VMAT for the same patient. 
TABLE 4. Dosimetric results for organs at risk in prostate SABR-VMAT plans using four arc arrangements

\begin{tabular}{|c|c|c|c|c|}
\hline & \multicolumn{4}{|c|}{ Avg SD (range) } \\
\hline & IFA & IPA & 2FA & 2PA \\
\hline \multicolumn{5}{|l|}{ Organs at risk } \\
\hline Rectum $D_{\text {mean }}(G y)$ & $\begin{array}{c}25.2 \pm 1.7 \\
(23.1-27.2)\end{array}$ & $\begin{array}{c}23.3 \pm 2.0 \\
(21.4-25.8)\end{array}$ & $\begin{array}{c}23.6 \pm 1.8 \\
(21.3-26.0)\end{array}$ & $\begin{array}{c}23.4 \pm 1.9 \\
(21.3-26.4)\end{array}$ \\
\hline Rectum $D_{2 \%}$ (Gy) & $\begin{array}{c}44.2 \pm 0.3 \\
(43.7-44.5)\end{array}$ & $\begin{array}{c}44.6 \pm 0.4 \\
(44.0-45.1)\end{array}$ & $\begin{array}{c}44.1 \pm 0.4 \\
(43.8-44.7)\end{array}$ & $\begin{array}{c}44.5 \pm 0.2 \\
(44.3-44.9)\end{array}$ \\
\hline Rectum $\mathrm{V}_{95 \%}(\%)$ & $\begin{array}{c}9.0 \pm 1.4 \\
(6.6-10.3)\end{array}$ & $\begin{array}{c}10.1 \pm 1.3 \\
(8.1-11.5)\end{array}$ & $\begin{array}{c}8.3 \pm 1.3 \\
(7.0-10.2)\end{array}$ & $\begin{array}{c}9.8 \pm 1.5 \\
(7.6-11.6)\end{array}$ \\
\hline Rectum $\mathrm{V}_{80 \%}(\%)$ & $\begin{array}{c}19.1 \pm 3.0 \\
(15.1-23.2)\end{array}$ & $\begin{array}{c}19.7 \pm 3.2 \\
(15.2-23.8)\end{array}$ & $\begin{array}{c}18.0 \pm 2.8 \\
(15.2-21.9)\end{array}$ & $\begin{array}{c}19.4 \pm 3.4 \\
(14.8-24.3)\end{array}$ \\
\hline Rectum $\vee_{50 \%}(\%)$ & $\begin{array}{c}71.0 \pm 8.8 \\
(61.1-80.1)\end{array}$ & $\begin{array}{c}53.9 \pm 9.4 \\
(41.9-63.7)\end{array}$ & $\begin{array}{l}60.0 \pm 11.1 \\
(46.9-77.4)\end{array}$ & $\begin{array}{c}54.1 \pm 9.0 \\
(42.5-66.7)\end{array}$ \\
\hline Rectum $\mathrm{V}_{20 \%}(\%)$ & $\begin{array}{c}90.2 \pm 2.5 \\
(87.7-93.4)\end{array}$ & $\begin{array}{c}90.0 \pm 2.7 \\
(87.1-94.1)\end{array}$ & $\begin{array}{c}89.6 \pm 3.0 \\
(85.6-93.5)\end{array}$ & $\begin{array}{c}90.0 \pm 2.8 \\
(87.3-94.0)\end{array}$ \\
\hline Bladder $\mathrm{D}_{\text {mean }}(\mathrm{Gy})$ & $\begin{array}{c}19.0 \pm 6.9 \\
(13.4-31.1)\end{array}$ & $\begin{array}{c}18.7 \pm 7.1 \\
(13.2-31.0)\end{array}$ & $\begin{array}{c}18.5 \pm 6.1 \\
(15.7-29.0)\end{array}$ & $\begin{array}{c}18.3 \pm 6.9 \\
(12.9-30.4)\end{array}$ \\
\hline Bladder $\mathrm{D}_{2 \%}(\mathrm{~Gy})$ & $\begin{array}{c}45.6 \pm 0.2 \\
(45.5-45.8)\end{array}$ & $\begin{array}{c}45.6 \pm 0.2 \\
(45.3-45.9)\end{array}$ & $\begin{array}{c}45.5 \pm 0.3 \\
(45.0-45.8)\end{array}$ & $\begin{array}{c}45.6 \pm 0.4 \\
(45.3-46.4)\end{array}$ \\
\hline Bladder $\mathrm{V}_{95 \%}(\%)$ & $\begin{array}{l}21.2 \pm 11.1 \\
(10.5-39.3)\end{array}$ & $\begin{array}{l}21.4 \pm 11.1 \\
(10.6-39.4)\end{array}$ & $\begin{array}{c}20.9 \pm 10.5 \\
(10.3-37.7)\end{array}$ & $\begin{array}{l}21.4 \pm 11.3 \\
(10.7-39.9)\end{array}$ \\
\hline Bladder $\mathrm{V}_{80 \%}(\%)$ & $\begin{array}{l}25.6 \pm 11.9 \\
(16.6-46.4)\end{array}$ & $\begin{array}{l}26.2 \pm 11.9 \\
(16.5-46.3)\end{array}$ & $\begin{array}{l}25.7 \pm 11.1 \\
(16.6-44.6)\end{array}$ & $\begin{array}{r}26.0 \pm 12.0 \\
(16.3-46.2)\end{array}$ \\
\hline Bladder $\mathrm{V}_{50 \%}(\%)$ & $\begin{array}{l}40.4 \pm 13.6 \\
(29.4-64.1)\end{array}$ & $\begin{array}{l}38.6 \pm 12.6 \\
(28.5-60.5)\end{array}$ & $\begin{array}{l}39.5 \pm 12.4 \\
(29.2-60.7)\end{array}$ & $\begin{array}{l}38.2 \pm 12.9 \\
(27.5-60.6)\end{array}$ \\
\hline Bladder $\mathrm{V}_{20 \%}(\%)$ & $\begin{array}{l}54.4 \pm 17.0 \\
(37.2-79.1)\end{array}$ & $\begin{array}{l}52.5 \pm 16.1 \\
(36.4-76.5)\end{array}$ & $\begin{array}{c}54.1 \pm 17.4 \\
(37.0-79.4)\end{array}$ & $\begin{array}{c}52.1 \pm 16.1 \\
(36.2-76.1)\end{array}$ \\
\hline $\begin{array}{l}\text { Left femoral head } \\
D_{\text {mean }}(G y)\end{array}$ & $\begin{array}{c}12.8 \pm 1.8 \\
(10.5-15.1)\end{array}$ & $\begin{array}{c}18.7 \pm 2.3 \\
(16.9-22.7)\end{array}$ & $\begin{array}{l}12.7 \pm 2.4 \\
(9.3-14.9)\end{array}$ & $\begin{array}{c}13.9 \pm 1.4 \\
(11.7-15.3)\end{array}$ \\
\hline $\begin{array}{l}\text { Left femoral head } \\
D_{2 \%}(G y)\end{array}$ & $\begin{array}{c}19.7 \pm 2.2 \\
(16.9-21.8)\end{array}$ & $\begin{array}{c}23.5 \pm 4.4 \\
(15.6-26.1)\end{array}$ & $\begin{array}{c}18.3 \pm 3.0 \\
(13.4-20.7)\end{array}$ & $\begin{array}{c}20.1 \pm 2.0 \\
(16.7-21.8)\end{array}$ \\
\hline $\begin{array}{l}\text { Right femoral } \\
\text { head } D_{\text {mean }}(G y)\end{array}$ & $\begin{array}{l}10.8 \pm 0.9 \\
(9.2-11.3)\end{array}$ & $\begin{array}{c}13.3 \pm 2.5 \\
(9.2-15.5)\end{array}$ & $\begin{array}{c}12.4 \pm 1.7 \\
(10.5-14.2)\end{array}$ & $\begin{array}{c}13.7 \pm 2.1 \\
(10.7-16.5)\end{array}$ \\
\hline $\begin{array}{l}\text { Right femoral } \\
\text { head } D_{2 \%}(G y)\end{array}$ & $\begin{array}{c}16.4 \pm 1.3 \\
(14.3-18.0)\end{array}$ & $\begin{array}{c}20.6 \pm 3.7 \\
(14.3-23.6)\end{array}$ & $\begin{array}{c}18.1 \pm 1.9 \\
(15.8-20.1)\end{array}$ & $\begin{array}{c}19.7 \pm 2.3 \\
(16.2-22.5)\end{array}$ \\
\hline
\end{tabular}

Avg. = average; $D_{5 \%}=$ the dose received at least $5 \%$ volume; $D_{\text {mean }}=$ the mean dose; $D_{\max }=$ the maximum dose; $D_{\min }=$ the minimum dose; $D_{50 \%}=$ the dose received at least $50 \%$ volume; $D_{95 \%}=$ the dose received at least $95 \%$ volume; $S D=$ the standard deviation; $V_{100 \%}=$ the volume received $100 \%$ of prescription dose.

TABLE 5. Average monitor unit and delivery time for prostate SBRT-VMAT plans using four arc arrangements

\begin{tabular}{lcccc}
\hline Beams & $\begin{array}{c}\text { 1FA } \\
\text { (Mean } \pm \text { SD) }\end{array}$ & $\begin{array}{c}\text { 1PA } \\
(\text { Mean } \pm \text { SD) }\end{array}$ & $\begin{array}{c}\text { 2FA } \\
\text { (Mean } \pm \text { SD) }\end{array}$ & $\begin{array}{c}\text { 2PA } \\
\text { (Mean } \pm \text { SD) }\end{array}$ \\
\hline $\mathrm{MU}$ & $1575 \pm 63$ & $1627 \pm 56$ & $1646 \pm 97$ & $1660 \pm 98$ \\
\hline Delivery time (min) & $1.01 \pm 0.02$ & $0.69 \pm 0.01$ & $2.00 \pm 0.01$ & $1.36 \pm 0.02$ \\
\hline
\end{tabular}

TABLE 6. TCP of prostate tumor and NTCP of OARs for four arc arrangement plans

\begin{tabular}{|c|c|c|c|c|}
\hline Beams & $\begin{array}{c}1 \mathrm{FA} \\
\text { (Mean } \pm \text { SD) }\end{array}$ & $\begin{array}{c}\text { 1PA } \\
\text { (Mean } \pm S D)\end{array}$ & $\begin{array}{c}\text { 2FA } \\
\text { (Mean } \pm S \mathrm{SD})\end{array}$ & $\begin{array}{c}\text { 2PA } \\
(\text { Mean } \pm S D)\end{array}$ \\
\hline \multicolumn{5}{|l|}{ TCP (\%) } \\
\hline Prostate & $93.35 \pm 0.08$ & $99.28 \pm 0.06$ & $93.32 \pm 0.08$ & $93.36 \pm 0.08$ \\
\hline \multicolumn{5}{|l|}{ NTCP (\%) } \\
\hline Rectum & $0.44 \pm 0.23$ & $0.61 \pm 0.21$ & $0.40 \pm 0.23$ & $0.56 \pm 0.22$ \\
\hline Bladder & $0.01 \pm 0.02$ & $0.01 \pm 0.03$ & $0.00 \pm 0.01$ & $0.00 \pm 0.02$ \\
\hline LT Femur & $0.00 \pm 0.00$ & $0.00 \pm 0.00$ & $0.00 \pm 0.00$ & $0.00 \pm 0.00$ \\
\hline RT Femur & $0.00 \pm 0.00$ & $0.00 \pm 0.00$ & $0.00 \pm 0.00$ & $0.00 \pm 0.00$ \\
\hline
\end{tabular}

time dependent. The delivery time for partial arc and full arc in single or double arc arrangements was similar because the delivery duration is limited by the gantry rotation speed and leaf speed, not the dose rate.

The MUs were observed to significantly increase with the number of arcs used in an SBRT-VMAT plan. The MU value of the 2FA and 2PA was up to $5 \%$ greater than that of the 1FA. This was in line with the previous study ${ }^{20}$, which reported the incensement of MUs in plans using double arcs compared to those with single arcs. However, the plan using 1FA for this study required lower MUs than the plan using 1PA. The ratio of delivery time for 1FA, 2FA, and 2PA compared to 1PA was between 1.5 and 3 . The use of 1PA appeared to reduce the treatment delivery time, which has obvious benefits for SBRT.

In this study, we compared the radiobiological impact among four arc arrangements within SBRTVMAT plans for prostate cancer. There were no obvious differences in the TPC and the NTCP for plans using four arc arrangements, excluding the NTCP value of the rectum. The NTCP difference of rectum was also small (within $0.2 \%$ ) among the four arc arrangements as shown in Table 6 . These mean that radiobiological outcomes have no difference relative to four arc arrangements. Furthermore, the TCP increase/decrease was correlated with $\mathrm{D}_{\text {mean' }}$ which is related to the mean dose. The mean dose of PTV for four arc arrangements showed no difference (Table 3). The NTCP of the rectum for the partial arc arrangements (1PA and 2PA) was higher than that of the full arc arrangements (1FA and 2FA). The reason for this is that the rectum includes the high-dose region with higher mean and maximum doses in plans using partial arc arrangements. Nevertheless, such an increased NTCP of the rectum is still within the acceptable range.

Limitation of this study is that there are no definitive clinical data on short- and long-term outcomes. This study focused mainly on the investigation of optimal treatment planning in prostate SBRT-VMAT. Therefore, future follow-up studies are required to evaluate the clinical outcome and toxicity for practice application of this technique.

\section{Conclusions}

Prostate SBRT-VMAT plans using four arc (1FA, 1PA, 2FA, and 2PA) arrangements offered high conformity for target volumes. This study demonstrated that prostate SBRT-VMAT using 1PA $\left(240^{\circ}\right.$ 

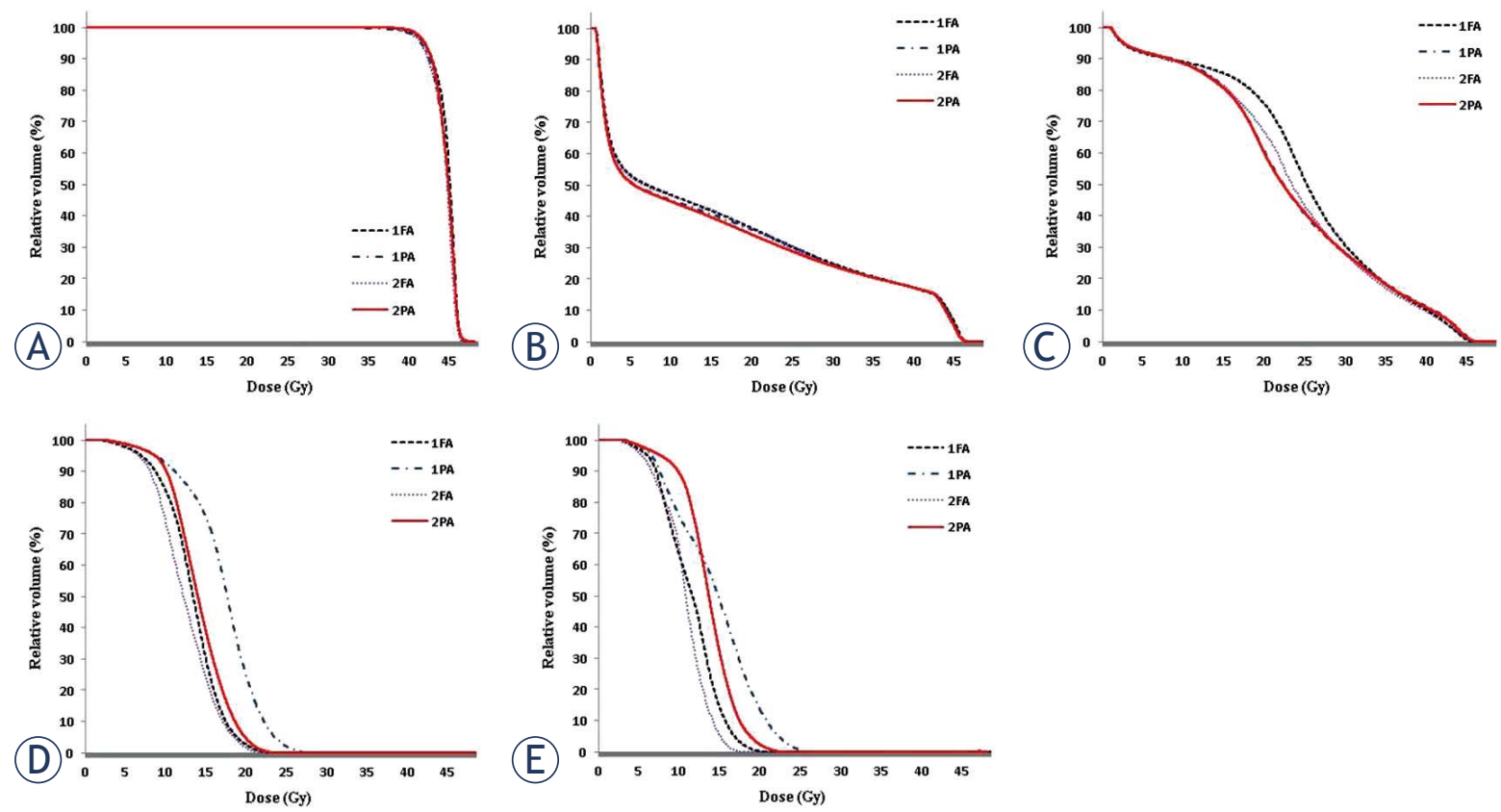

FIGURE 3. Average dose-volume histograms of the (A) PTV, (B) bladder, (C) rectum, (D) left femoral head, and (E) right femoral head from prostate SBRT-VMAT plans for four arc arrangements (IFA, IPA, 2FA, and 2PA).

to $120^{\circ}$ ) showed reasonably fast delivery time and produced equivalent target coverage and better rectum sparing, although the near-to-maximum dose and mean dose of the left and right femoral heads increased slightly. However, the doses in both femoral heads remained well within the clinical normal tissue tolerance. For evaluating the radiobiological metrics, all plans using four arc arrangements produced comparable TCP for prostate tumors and NTCP for OARs. Therefore, it was concluded that the use of 1PA was an attractive choice for treating prostate cancer using SBRT-VMAT.

\section{Author Contribution}

Conception and design of the study: JBC TSS. Coordination of the study: SWK JSK JWL. Case selection, radiation treatment planning, and analysis: KYE CHS JSK JYK JBC. Manuscript preparation: JBC SWK. Manuscript revision and editing: JBC JSK IAK TSS. Manuscript approval: all authors.

\section{Acknowledgments}

This research was supported by a grant of the Korea Health technology R\&D Project through the Korea Health Industry Development Institute (KHIDI), funded by the Ministry of Health \& Welfare,
Republic of Korea. (Grant Number: HI15C0638) and by a grant (2014R1A2A1A10050270) from the Mid-career Researcher Program through the National Research Foundation of Korea funded by the Ministry of Science, ICT\&Future Planning .

\section{References}

1. Zelefsky MJ, Leibel SA, Gaudin PB, Gaudin P, Kutcher G, Fleshner N, Venkatramen ES, Reuter V, Fair W, Ling CC, Fuks Z. Dose escalation with three dimensional conformal radiation therapy affects the outcome in prostate cancer. Int J Radiat Oncol Biol Phys 1998; 41: 491-500. doi:10.1016/ s0360-3016(98)00091-1

2. Chung JB, Kim JS, Kim IA, Lee JW, Cho W, Suh TS. The effect of photon energy on the intensity-modulated radiation therapy plan for prostate cancer: a planning study. J Korean Phys Soc 2013; 19: 183-188. doi:10.3938/ jkps.59.183

3. Alongi $F$, Cozzi L, Arcangeli S, Iftode C, Comito T, Villa E, et al. Linac based SBRT for prostate cancer in 5 fractions with VMAT and flattening-filter-free beams: preliminary report of a phase II study. Radiat Oncol 2013; 8: 171. doi:10.1016/s0167-8140(15)32356-2

4. Martinez AA, Yan D, Lockman D, Brabbins D, Kota D, Sharpe M, Jaffray DA, Vicini, Wong J. Improvement in dose escalation using the process of adaptive radiotherapy combined with three-dimensional conformal or intensitymodulated beams for prostate cancer. Int J Radiat Onco. Biol Phys 2001; 50: 226-234. doi:10.1016/s0360-3016(01)01552-8

5. Nutting CM, Convery DJ, Cosgrove VP, Rowbottom C, Padhani AR, Webb S, Dearnaley DP. Reduction of small and large bowel irradiation using an optimized intensity-modulated pelvic radiotherapy technique in patients with prostate cancer. Int J Radiat Oncol Biol Phys 2000; 48: 649-656. doi:10.1016/ s0360-3016(00)00653-2

6. Pollack A, Zagars GK, Starkschall G, Antolak JA, Lee J, Huang E, Eschenbach AC, kuban DA, Rosen I. Prostate cancer radiation dose response: Results of the M. D. Anderson phase III randomized trial. Int J Radiat Oncol Biol Phys. 2002; 53(5): 1097-1105. doi:10.1016/s0360-3016(02)02829-8 
7. Zelefsky MJ, Fuks Z, Hunt M, Yamada Y, Marion C, Ling CC, Amols $\mathrm{H}$, Venkatraman ES, Leibel SA. High-dose intensity modulated radiation therapy for prostate cancer: early toxicity and biochemical outcome in 772 patients. Int J Radiat Oncol Biol Phys 2002; 53: 1111-1116. doi:10.1016/ s0360-3016(02)02857-2

8. McGrath SD, Matuszak MM, Yan D, Kestin LL, Martinez AA, Grills IS Volumetric modulated arc therapy for delivery of hypofractionated stereotactic lung radiotherapy: a dosimetric and treatment efficiency analysis. Radiother Oncol 2010; 95: 153-157. doi:10.1016/j.radonc.2009.12.039

9. Lee E, Kim TG, Park HC, Yu Jl, Lim DH, Nam H, Lee H, Lee JH. Clinical outcomes of stereotactic body radiotherapy for spinal metastases from hepatocellular carcinoma. Radiat Oncol J 2015; 33: 217-225. doi:10.1016/j. radonc.2009.12.039

10. Mancosu P, Castiglioni S, Reggiori G, et al. Stereotactic body radiation therapy for liver tumours using flattening filter-free beam: Doseimetric and technical considerations, Radiat Oncol 2012; 7: 16. doi:10.1186/1748-717x-7-16

11. Vassiliev O, Kry SF, Chang JY, Balter PA, Titt U, Mohana R. Stereotactic radiotherapy for lung cancer using a flattening filter free clinic. J App Clin Med Phys 2009; 10: 14-21. doi:10.1120/jacmp.v10i1.2880

12. Park SY, Oh D, Park HC, Kim JS, Kim JS, Shin EH, Kim HY, Jung SH, Han Y Comparison of dose distribution in spin radiosurgery plans: simultaneously integrated boost and RTOG 0631 protocol. Prog Med Phys 2014; 25: 176183. doi:10.14316/pmp.2014.25.3.176

13. Lee $S$, Chun M, Lee MJ. Stereotactic body radiotherapy for solitary spine metastasis. Radiat Oncol J 2013; 31: 206-266. doi:10.3857/roj.2013.31.4.260

14. Lin YW, Lin KH, Ho HW, Lin HM, Lin LC, Lee SP, Chui CH. Treatment plan comparison between stereotactic body radiation therapy techniques for prostate cancer: Non-isoncentric CyberKnife versus isocentric RapidArc. Phys Med 2014; 30: 654-661. doi:10.1016/j.ejmp.2014.03.008

15. Katz AJ. CyberKnife radiosurgery for prostate cancer. Technol Cancer Res Treat 2010; 9: 463-72. doi:10.1177/153303461000900504

16. King CR, Lehmann J, Adler JR, Hai J. CyberKnife radiotherapy for localized prostate cancer; rationale and technical feasibility. Technol Cancer Res Treat 2003; 2: 25-30. doi:10.1177/153303460300200104

17. Chen LN, Suy S, Uhm S, Oermann EK, Ju AW, Chen V, Hanscom HN, Laing S, Kim JS, Lei S, et al. Stereotactic Body Radiation Therapy (SBRT) for clinically localized prostate cancer: the Georgetown University experience. Radiat Oncol 2013; 8: 58. doi:10.1186/1748-717X-8-58

18. Rana $\mathrm{S}$, Cheng CY. Feasibility of the partial-single arc technique in RapidArc planning for prostate cancer treatment. Chin J Cancer 2013; 32: 546-552. doi:10.5732/cjc.013.10077

19. Chow JC, Jiang R. Prostate volumetric-modulated arc therapy: dosimetry and radiobiological model variation between the single-arc and doublearc technique. J Appl Clin Med Phys 2013; 14: 3-12. doi:10.1120/jacmp. v14i3.4053

20. Koo T, Chung JB, Eom KY, Seok JY, Kim IA, Kim JS. Dosimetric effect the acuros $\mathrm{XB}$ and anisotropic analytic algorithm on volumetric modulated arc therapy planning for prostate cancer using an endorectal balloon. Radiat Oncol 2015; 10: 48. doi:10.1186/s13014-015-0346-3

21. Kim JS, Chung JB, Kim IA, Eom KY. Dosimetric effects of endorectal balloons on intensity-modulated radiation therapy plans for prostate cancer. J Korean Phys Soc 2013; 63: 1637-1643. doi:10.3938/jkps.63.1637

22. Murray $\amalg$, Cosgrove V, Lilley J, Sykes J, Thompson CM, Frank K, Sebag Montefiore D, Henry AM. Developing a class solution for prostate stereotactic ablative body radiotherapy (SABR) using volumetric arc therapy. Radiat Oncol 2014; 110: 298-302. doi:10.1016/j.radonc.2013.10.036

23. Shaw E, Kline R, Gillin M, Souhami L, Hirschfeld A, Dinapoli R, Martin L. Radiation Therapy Oncology Group: radiosurgery quality assurance guidelines. Int J Radiat Oncol Biol Phys 1993; 27: 1231-1239. doi:10.1016/0360 3016(93)90548-a

24. van't Riet A, Mak AC, Moerland MA, Elders LH, van der Zee W. A conformation number to quantify the degree of conformality in brachytherapy and external beam irradiation: application to the prostate. Int J Radiat Oncol Biol Phys. 1997; 37: 731-736. doi:10.1016/s0360-3016(96)00601-3

25. Oinam AS, Singh L, Shukla A, Ghoshal S, Kapoor R, Sharma SC. Dose volume histogram analysis and comparison of different radiobiological models using in-house developed software. J Med Phys 2011; 36: 220-229. doi:10.4103/0971-6203.89971
26. Gay HA, Niemierko A, A free program for calculating EUD-based NTCP and TCP in external beam radiotherapy. Phys Med 2007; 23: 115-125. doi:10.1016/j.ejmp.2007.07.001

27. Emami B, Lyman J, Brown A, Coia L, Goitein M, Munzenrider JE, et al. Tolerance of normal tissue to therapeutic irradiation. Int J Radiat Oncol Biol Phys 1991; 21: 109-122. doi:10.1016/0360-3016(91)90171-Y

28. Rana S, Cheng CY. Radiobiological impact of planning techniques for prostate cancer in terms of tumor control probability and normal tissue complication probability. Ann Med Health Sci Res 2014; 4: 167-172. doi:10.4103/2141-9248.129023

29. Seisen T, Drouin SJ, Phé V, Parra J, Mozer P, Bitker MO, Cussenot O, Rouprêt M. Current role of image-guided robotic radiosurgery (Cyberknife $\left.{ }^{\circledR}\right)$ ) for prostate cancer treatment. BJU Int. 2013; 111: 761-766. doi:10.1111/ bju. 12000

30. Chow JCL and Jiang R. Prostate volumetric-modulated arc therapy: dosimetry and radiobiological variation between the single-arc and doublearc technique. J App Clin Med Phy 2014; 14: 3-12. doi:10.1120/jacmp. v14i3.4053 